\section{Medication Error - Learning From It}

\section{Dear Editor,}

$\mathrm{T}$ here have been many instances in medical practice of wrong injections administered to patients, with varying effects. Individual cases have resulted in serious outcome or even death to patients, and some have been the subject of litigation and media attention. Examples of serious medication errors that have been reported include error in the calculation of the dose, selection of the wrong drug and selection of the wrong diluent [1]. In the present era, when the consumer expects a zero error outcome, many such cases of inadvertent injections administered, are not reported. However, errors do take place, and such instances can be used as learning opportunities for better patient care in future [2]. Negligent actions should be distinguished from honest mistakes. Ethics, professional policy and the law, as well as the relevant empirical literature, suggest that timely and candid disclosure of such errors should be standard practice [3]. Timely reporting and learning from mistakes are the positive aspects of medical errors.

Here, we report a case where a newborn baby ( $\mathrm{Rh}$ positive) was wrongly administered anti-D gamma globulin. Though passage of maternal Rhesus antibodies ( $\operatorname{IgG}$ ) to babies is responsible for Haemolytic Disease of Newborn', the effect of administering anti$\mathrm{D}$ gamma globulin injection to a $\mathrm{Rh}$ positive baby has not been reported so far. Reactions due to $\mathrm{Rh}$ antibodies are usually less severe than those caused by ABC incompatibility, since they do not activate the complement. Also, a single dose $(300 \mu \mathrm{g})$ of anti-D gamma globulin contains sufficient anti D to neutralise $15 \mathrm{ml}$ of RBCs. Hence, administering anti-D gamma globulin to Rh positive babies may result in mild anaemia due to immune mediated haemolysis. Auto agglutination and/or presence of spherocytes are commonly described as hallmark laboratory findings. Direct Coombs test is usually negative due to low antibody titre.

A term male neonate, born by normal vaginal delivery, was accidentally injected (subsequently realised by nursing staff) with $300 \mu \mathrm{g}$ of anti-D gamma globulin intramuscularly, after 24 hours of birth. The baby was the first child of a young primi lady, with uncomplicated antenatal period. Her blood group was 'B' negative and there was no past history of abortions, still births or having received blood transfusion. Indirect coombs test was negative antenatally. The baby's blood group was 'O' positive and cord blood samples revealed bilirubin of $2 \mathrm{mg} / \mathrm{dl}$ and haemoglobin of 17 gm/dl.

The baby was examined immediately for signs of allergic/ anaphylactic reaction. Baby was constantly monitored (clinical and laboratory) for evidence of haemolysis. On day four, the baby developed increased jaundice (serum bilirubin $16 \mathrm{mg} / \mathrm{dl}$ ). On day five and six, there was laboratory evidence of mild haemolysis in the blood. Haemoglobin level had dropped to $15 \mathrm{gm} / \mathrm{dl}$ and serum bilirubin (unconjugated) had peaked at $18 \mathrm{mg} / \mathrm{dl}$. Peripheral blood smear revealed polychromasia with increased spherocytes (>30\%). Reticulocytosis was present and direct coombs test was negative. The baby was managed by phototherapy with complete recovery. Hereditary spherocytosis was excluded based on family history, other laboratory parameters and monitoring at subsequent follow ups. Live vaccines were withheld from the immunisation schedule for 3 months.

\section{References}

1. Institute of Medicine, Committee of quality of health care in America. To err is human: building a safer health system, Washington (DC). National Academies Press 1999.

2. An organisation with a memory. A report on learning from adverse events in the NHS, London(UK): Department of Health (UK), 2000.

3. Kalra J, Massey KL, Mulla A. Disclosure of medical error: policies and practice. J R Soc Med 2005; 98: 307-9.

\section{Lt Col AN Prasad*}

"Classified Specialist (Paediatrics), Military Hospital, Mhow-1.

Received : 06.09.2005; Accepted : 08.07.2006

\title{
ANSWERS TO MCQ
}

$\begin{array}{llll}1-\mathrm{b} & 2-\mathrm{c} & 3-\mathrm{c} & 4-\mathrm{a} \\ 5-\mathrm{a} & 6-\mathrm{b} & 7-\mathrm{b} & 8-\mathrm{b} \\ 9-\mathrm{d} & 10-\mathrm{c} & 11-\mathrm{b} & 12-\mathrm{e} \\ 13-\mathrm{b} & 14-\mathrm{d} & 15-\mathrm{d} & \end{array}$

